\title{
A Posição de Jovens de Ensino Médio Sobre o Risco e Testagem do HIV/aids
}

\author{
Alice Maggi", Aline Giasson, \& Luísa Verza \\ Universidade de Caxias do Sul, Caxias do Sul, Brasil
}

\begin{abstract}
RESUMO
O objetivo do estudo foi caracterizar a posição dos jovens, no que se refere ao HIV/aids, incluindo a sua autoavaliação, a exposição ao risco de contrair o vírus e a testagem. Participaram 1016 estudantes, sendo utilizado questionário com 42 questões. A autoavaliação do conhecimento sobre HIV/aids demonstrou ser satisfatória, em 68,5 \% dos participantes. Há associação significativa ( $<<0,05)$, entre o jovem buscar a testagem e considerá-la necessária e entre buscar a testagem e conhecer algo sobre o assunto. Os resultados sugerem que as futuras campanhas preventivas focalizem as especificidades dos jovens, orientando e potencializando os espaços de promoção de saúde, na família, na escola e na comunidade.
\end{abstract}

Palavras-chave: jovens; comportamento de risco; testagem; HIV; aids.

\section{ABSTRACT \\ The Position of High School Youngsters About HIV/aids Risk and Testing}

The aim of this study was to characterize the position of young people in relation to HIV/aids, including their self-assessment, exposure to the risk of contracting the virus and testing. A total of 1016 students participated, and a questionnaire with 42 questions was used. The self-assessment of knowledge about HIV/aids has proved satisfactory in $68.5 \%$ of participants. There is a significant association $(\mathrm{p}<0,05)$ between seeking testing and consider it necessary, and between seeking testing and knowing something about the matter. The results suggest that the next preventive campaigns should focus on specific traits of young people, directing and improving the places dedicated to health promotion, in the family, schools and communities

Keywords: young high school; risk behavior; testing; HIV; aids.

O Programa Nacional DST e Aids (2007), do Ministério da Saúde, contempla a prevenção, entre os demais focos do trabalho relativo ao controle da epidemia, no país, como o diagnóstico, o aconselhamento e a medicação. Os jovens adolescentes constituem um contingente populacional prioritário das ações de prevenção, para controle de HIV/aids, DSTs e drogas. Mais da metade do número de pessoas que são infectadas com o HIV, no mundo, adquire o vírus, antes de completar 25 anos (Santos \& Santos, 1999). No Brasil, 49,4\% das pessoas contaminadas estão entre a faixa etária de 13 e 34 anos, destacando-se que $10 \%$ deles estão próximos da adolescência e foram infectados pelas suas mães, durante a gestação (Ayres, 2007). Esses jovens, de uma maneira geral, necessitam ter conhecimentos e habilidades que os auxiliem na adoção de comportamentos de prevenção, mais do que serem foco de campanhas preventivas. Isso porque duas décadas de prevenção e avanços, no tema do HIV/aids, ainda desafiam especialistas, no sentido de explorar os obstáculos e outros códigos que interme-

* Endereço para correspondência: Alice Maggi, Centro de Ciências Humanas, Universidade de Caxias do Sul, Rua Francisco Getúlio Vargas, 1130, Bloco E, Petrópolis, Caxias do Sul, RS, CEP 95070-560. E-mail: amaggi@ucs.br e amaggi@terra.com.br. Apoios: Universidade de Caxias do Sul, Laboratório de Pesquisa em HIV/AIDS da Universidade de Caxias do Sul, Fundação de Amparo à Pesquisa do Estado do Rio Grande do Sul, Prof. Dr. Carlos Eduardo Pinent - Estatística. 
deiam a informação e a adoção de medidas de proteção (López, 2004).

Apenas 14\% das jovens, de 15 a 19 anos, usam algum método contraceptivo e, entre as meninas brasileiras, a principal via de infecção pelo HIV são as relações heterossexuais (Niimi, 2000). Mais recentemente, o estudo de Trajman e cols. (2003), com 945 jovens, entre 13 e 21 anos, de dez escolas da região do sudeste brasileiro, indicou que $34 \%$ delas declararam ter utilizado preservativo sempre, em todas as relações sexuais, muito embora 94\% conhecessem a proteção relativa ao preservativo. Paiva (2006), por sua vez, descreveu que, num estudo de intervenção, realizado com 394 alunos de escolas públicas, também da Região Sudeste, o uso continuado de preservativos era baixo $(33 \%)$ e que existiam diferenças significativas, entre homens e mulheres, no trato da sexualidade e da prevenção.

O Brasil, mesmo sendo modelo no controle e combate da epidemia de HIV/aids, ainda mostra fragilidades, em algumas questões pontuais; entre elas, as sociocomportamentais e psicossociais, que se revelam como desafio aos pesquisadores e clínicos da área da saúde, quando se pensa na prevenção primária, que evita das pessoas se infectarem. Isso porque a oferta de suporte psicossocial constitui-se numa estratégia fundamental de prevenção secundária, com desdobramentos individuais e coletivos (Bastos \& Hacker, 2006).

A literatura especializada tem se dedicado a aprofundar a reflexão sobre os jovens, em tempos de HIV/aids (Camargo \& Bárbara, 2004; Dall'Agnol, 1999; Paiva, 2006), preocupando-se em detalhar as concepções dos jovens sobre o assunto e, também, desenvolver estratégias que os sensibilizem para o autocuidado, envolvendo, aí, também, as doenças sexualmente transmissíveis. No contexto local, escassos são os estudos que indicam, precisamente, o cenário, a fim de que estratégias de maior resolutividade possam ser implantadas, com sucesso. Muitos deles se ocuparam da população já infectada, entrevistando usuários de serviço de referência na região e, por isso mesmo, alinhado à denominada "prevenção secundária” (Duarte, Mezzomo, \& Bordin, 2007).

À parte dos avanços biológicos para o tratamento da doença, é imperioso debruçar-se sobre as implicações psicossociais que compõem o cenário do HIV/aids. É relevante conhecer os aspectos psicosso- ciais e articulá-los com possíveis contribuições teóricas e avanços metodológicos, tanto na abordagem dessa jovem população, como, também, na proposição de novas alternativas de acesso a esse grupo, responsável pelo futuro da humanidade. Isso porque a adolescência, conforme propõe Jerusalinsky (2004), é um estado de espírito, independentemente da idade. Um estado de espírito adolescente é um estado juvenil, talvez indeciso. É uma passagem entre a infância e a vida adulta que atravessa esse estado de indecisão, que convoca a um eminente desfecho. Essa passagem vai do estado de proteção, que caracteriza a infância, ao estado de exposição, que caracteriza o adulto. $\mathrm{O}$ adulto é, então, um ser exposto, porque cada um de seus atos e de suas palavras tem consequências, sob sua própria responsabilidade e autonomia.

Nessa direção, a revisão de literatura indica o quanto a temática dos jovens e o HIV/aids se relaciona com o comportamento sexual e todas suas idiossincrasias, também vinculadas ao próprio comportamento sexual e às doenças sexualmente transmissíveis, razão pela qual as investigações devem contemplar tão complexo cenário (Figueiró \& Ribeiro, 2006; Maticka-Tyndale \& Brouillard-Coyle, 2006; Taylor, Dlamini, Kagoro, Jinabhai, \& Vries, 2003).

O objetivo do presente estudo é compreender e caracterizar, portanto, a posição dos jovens, estudantes de ensino médio, no que se refere ao HIV/aids, quanto a sua própria autoavaliação sobre o tema HIV e a percepção das situações de exposição ao risco de contrair o vírus, como, também, a posição deles, diante da necessidade de testagem, para a verificação da presença do vírus. Isso porque conhecer e preocupar-se com seu status, diante do vírus, também, constitui-se como um forte elemento preventivo, para o jovem, em tempos de HIV/aids.

\section{MÉTODO}

\section{Participantes}

Participaram da pesquisa 1016 estudantes, sendo $461(45,37 \%)$ alunos da primeira série, 223 (21,95\%), da segunda série e 328 (32,28\%), da terceira série do ensino médio. A média de idade dos participantes foi de 18,9 anos, sendo $347(34,2 \%)$ do sexo masculino e $668(65,7 \%)$ do sexo feminino. Destes participantes, $963(94,8 \%)$ eram solteiros e $565(55,6 \%)$ responderam já terem tido relação sexual. Das jovens que res- 
ponderam o questionário, $14(1,4 \%)$ eram gestantes. Referente à raça, houve maior predominância da raça branca, 645 (63,5\%), seguida da parda, $156(15,4 \%)$. $\mathrm{Na}$ amostra, predominaram a religião católica - 732 $(72,0 \%)$ - e a evangélica - $121(11,9 \%)$. A renda familiar da maioria - $341(33,6 \%)$ - foi informada como de $\mathrm{R} \$ 900,00$ a $\mathrm{R} \$ 1.799,00$, e de $\mathrm{R} \$ 300,00$ a $\mathrm{R} \$ 899,00$, para $30,9 \%$ (314) deles.

Os participantes eram estudantes de nove, das dezessete, escolas estaduais, de ensino médio, de uma cidade de porte médio, do Estado do Rio Grande do Sul, distribuídos em escolas, aqui, denominadas como A $(30,8 \%), B(13,0 \%), C(12,5 \%), D(12,2 \%)$, E $(11,2 \%), \mathrm{F}(9,4 \%), \mathrm{G}(8,5 \%), \mathrm{H}(1,7 \%)$ e I $(0,7 \%)$, a fim de dar maior representatividade à composição da amostra. Em algumas das escolas, a coleta das informações foi realizada em mais de um turno: manhã, tarde e noite, sendo que o total de participantes corresponde a, aproximadamente, $10 \%$ dos estudantes de ensino médio, do município, à época da realização do projeto de pesquisa que deu origem ao presente artigo.

\section{Instrumento}

Foi utilizado um questionário, contendo 42 questões, abordando dados sociodemográficos, situações objetivas e hipotéticas, com opções de escolhas simples e depoimento espontâneo por escrito, em relação ao grau de informação sobre o HIV, testagem, risco de exposição e notificação de parceiros, em caso de contaminação. Os questionários apresentavam-se em três distintos modelos, A, B e C, para garantir o sigilo das respostas dos participantes, em que, para algumas das questões - 14, 16, 17, 18, 38 e 39 -, as respostas tinham alteradas as ordens das opções. O questionário foi elaborado pelo grupo de pesquisa e foi adaptado de outro já aplicado, em uma amostra com estudantes universitários, em estudo anterior (Wagner, Maggi, Souza, \& Souza, 2010).

\section{Procedimentos}

Após a aprovação do Comitê de Ética em Pesquisa, da universidade local, a coleta de dados foi iniciada, por meio de contato telefônico com as escolas, após o consentimento da coordenadoria de ensino da região. No contato, era explicado o projeto de pesquisa, para o responsável do turno, e marcado um horário, no qual a direção pudesse receber as pesquisadoras. No conjunto, a receptividade das direções das escolas foi boa, assim como por parte dos alunos e dos professores. Em algumas escolas, houve maior resistência, por parte dos professores, quanto à coleta, visto que, para alguns, significava interferir nas rotinas das aulas. Entretanto, outros professores não tinham esta percepção, se interessando bastante pela pesquisa e reforçando a sua importância. Nenhuma escola se recusou a participar do estudo e apenas uma mãe, de um dos participantes, fez contato com o Curso de Psicologia através do telefone indicado, no termo de consentimento - porque tinha dúvidas quanto ao espaço em que deveria assinar a permissão, para participação do (a) filho (a) adolescente, no projeto. Tal situação confirma a possibilidade, prevista no Termo de Consentimento Livre e Esclarecido, de que outros esclarecimentos poderão ser fornecidos, caso a primeira apresentação não tenha sido suficiente. Há que se destacar que as orientações eram dadas aos estudantes, que, por sua vez, levavam o documento para casa, quando menores de idade. Sendo assim, compreende-se que eventuais dificuldades de compreensão pudessem ocorrer. Os jovens, na maioria das vezes, aceitaram participar da pesquisa e se interessavam por ela, mas muitos se esqueciam de trazer os termos de consentimento assinados, o que impossibilitava a sua participação.

Primeiramente, era explicado o projeto de pesquisa e os termos de consentimento, que eram, imediatamente, entregues. E, em outro dia, era realizada a aplicação do questionário, para aqueles que haviam trazido os termos de consentimento assinados pelos pais ou responsáveis (no caso de menores de 18 anos) ou por eles mesmos (no caso de maiores de 18 anos). Estes termos assinados eram recolhidos, ficando um para o participante e outro para o arquivo da pesquisa, com a assinatura do responsável pela aplicação. Os participantes deveriam escrever exclusivamente na folha de resposta e, ao final, eram recolhidos o questionário e a folha de respostas preenchida. Em algumas escolas, foi necessário ir mais de duas vezes, devido à quantidade de turmas existentes. Também em função do número de turmas, em algumas das escolas, retornou-se após um período, a fim de não sobrecarregar, em semanas consecutivas, o ingresso, em sala de aula. Em outras escolas, foi necessário retornar outro dia, devido à agenda específica daquele dia, que impedia a liberação dos estudantes, para participarem.

Os questionários respondidos eram conferidos, para que não houvesse nada escrito neles. Quando isto 
acontecia, eles eram excluídos e substituídos por outros. Possivelmente, por se tratar de uma amostra composta por participantes adolescentes, muitos interferiam e questionavam algumas das perguntas, permitindo o enriquecimento da própria observação, mostrando, também, as dúvidas mais frequentes, qualificando ainda mais as orientações, ao longo do processo de coleta de informações.

As respostas dos participantes foram registradas, em uma planilha Excel, nos modelos A, B e C, sendo, ainda, necessário fazer a conversão dos modelos B e C em A. As informações foram analisadas, pelo software Statistical Package for the Social Sciences - SPSS , na versão mais recente, por meio de estatística descritiva e, também, com testes estatísticos, como Fisher. Posteriormente, os dados qualitativos foram, também, inseridos, nessa planilha, completando o banco de dados, relativo ao estudo.

Apenas em uma escola, houve contato da bolsista de iniciação científica, com a estagiária de psicologia escolar, o que permitiu o trabalho em conjunto, facilitando a integração e a visualização de práticas, a partir do próprio projeto. Assim, pôde-se fazer uma troca de conhecimentos e informações muito produtivos, em que a pesquisa aproxima as práticas psicológicas das demandas da clientela, sempre intermediando com os serviços já disponíveis, na cidade (por exemplo, materiais de divulgação do serviço referência, na cidade). Ressalta-se, uma vez mais, que todas as ações contaram com a supervisão da coordenadora do projeto e a equipe do laboratório de pesquisa, que apoiou a reali- zação deste estudo, e com o conhecimento da supervisora acadêmica, da estagiária, evitando a mescla de papéis.

Mesmo que o projeto não tenha contemplado estratégias de interferência ou intervenção junto ao grupo de estudantes de ensino médio, ao final da aplicação, era disponibilizado o endereço eletrônico e o 0800 do Ministério da Saúde e, a partir da segunda metade de coleta de informações, iniciou-se a disponibilização de folders informativos, na escola, sobre o vírus, formas de transmissão e demais cuidados. Isso porque se constatou que o convite a participar da pesquisa mobilizava, nos jovens, curiosidades e perguntas. Concluída a coleta de dados, foi enviada uma carta de agradecimento, para cada escola.

\section{RESULTADOS}

A Tabela 1 ilustra a distribuição das frequências dos participantes, quanto à informação que eles possuem, sobre o HIV, ou seja, uma autoavaliação do conhecimento, sobre o assunto. Nota-se que a percentagem que se diz conhecer bem ou muito bem foi predominante e a maioria, $92,10 \%$, afirmou já ter assistido algo, sobre HIV/aids. Além disso, quando indagados sobre a transmissão vertical, $89,20 \%$ responderam que a gestante com HIV transmite o vírus para o bebê e $2,90 \%$ afirmaram que a gestante com HIV não transmite o vírus para o bebê, percentagem que era esperada, visto o quanto é disseminada tal informação, nos veículos de comunicação e saúde.

Tabela 1

Autoavaliação e Conhecimento Sobre HIV/aids ( $n=1016)$

\begin{tabular}{lll}
\hline RESPOSTAS & $\mathrm{F}$ & $\%$ \\
\hline Conheço bem & 600 & 59,1 \\
Conheço pouco & 285 & 28,1 \\
Conheço muito bem & 96 & 9,4 \\
Conheço muito pouco & 22 & 2,2 \\
Não conheço nada & 6 & 0,6 \\
Nula ou em branco & 7 & 0,7 \\
Assisti algo sobre HIV/ Aids & 936 & 92,1 \\
Não assisti nada sobre HIVI Aids & 80 & 7,9 \\
Gestante com HIV transmite o vírus para o bebê & 906 & 89,2 \\
Gestante com HIV não transmite o vírus para o bebê & 29 & 2,9 \\
\hline
\end{tabular}


No entanto, na Tabela 2, que ilustra os itens em que o questionário abordou, pontualmente, algumas possibilidades de exposição ao risco de contaminarem-se com HIV, os resultados foram distintos. A Tabela 2 reúne, portanto, as respostas afirmativas, dos participantes, diante dos itens mencionados como possibilidades de exposição ao risco.

Era esperado que todas as respostas relacionadas ao contágio via sexual ou sanguínea tivessem uma frequência semelhante, próxima aos $100 \%$, enquanto que aquelas respostas, relacionadas a outras formas de contágio, tivessem uma frequência mínima. Destacase que, entre as possibilidades de exposição ao risco, via contato sexual e sanguíneo, as diferenças foram explicadas pelas crenças dos jovens, quanto às práticas sexuais, já que, quando se tratou de sexo sem proteção, com parceiros diferentes, o percentual foi de $91,9 \%$ e, quando se tratou de parceiro conhecido, o percentual foi de $73,3 \%$. No que se refere ao contato sanguíneo, o mesmo foi observado: contato com sangue contaminado, o percentual foi de $82,5 \%$ e contato com sangue, cuja origem era desconhecida, quanto à contaminação, registrou-se um percentual de 55,6\%. $\mathrm{E}$, apesar de todas as campanhas informativas, constatou-se um percentual de $4,5 \%$ que afirmou que outras formas de contato não sexuais constituem-se numa forma de exposição ao risco.

Tabela 2

As Situações de Exposição ao Risco ao HIV/aids ( $n=1016$ )

\begin{tabular}{lll}
\hline SITUAÇÕES DE RISCO & $f$ & $\%$ \\
\hline Sexo sem camisinha, com parceiros diferentes & 934 & 91,9 \\
Compartilhamentos de agulhas e seringas de usuários de drogas injetáveis & 933 & 91,8 \\
Sexo casual, sem camisinha & 920 & 90,6 \\
Contato com sangue contaminado & 838 & 82,5 \\
Transfusão de sangue & 795 & 78,2 \\
Tatuagem, piercing, maquiagem definitiva, manicure sem material esterilizado & 769 & 75,7 \\
Sexo sem camisinha, com parceiro conhecido & 745 & 73,3 \\
Tratamento dentário ou médico com material não esterilizado & 692 & 68,1 \\
Sexo sem camisinha, com parceiro fixo & 568 & 55,9 \\
Contato com sangue (não sabe se contaminado ou não) & 565 \\
Acidente de trabalho/trânsito & 368 & 55,6 \\
Picada de insetos & 233 \\
Beijo na boca com pessoa contaminada & 174 \\
Uso de banheiros, copos, pratos, talheres, toalhas, partilhados com o portador do vírus HIV & 123 \\
Secreções (lágrimas, saliva, suor, espirro, tosse) & 116 \\
Abraços e outros contatos físicos (não sexuais) & 46,2 \\
\hline
\end{tabular}

As Tabelas 3, 4 e 5 apresentam os resultados referentes às associações entre os participantes terem feito o teste para o HIV e considerarem necessário a realização do teste, ter conhecimento sobre o HIV e, finalmente, quanto a terem assistido algo sobre o assun- to. Isso porque interessava compreender em que contexto os jovens buscaram conhecer o seu status sorológico, considerando o possível impacto das campanhas preventivas ou mesmo a sua própria posição do assunto. 
Tabela 3

Teste HIV e Necessidade do Teste HIV $(n=1016)$

\begin{tabular}{|c|c|c|c|c|c|c|c|c|c|c|}
\hline \multirow{3}{*}{ NECESSIDADE DO TESTE } & \multicolumn{10}{|c|}{ TESTE DO HIV } \\
\hline & \multicolumn{2}{|c|}{ SIM } & \multicolumn{2}{|c|}{ NÃO } & \multicolumn{2}{|c|}{$\begin{array}{l}\text { NULO OU } \\
\text { BRANCO }\end{array}$} & \multicolumn{2}{|c|}{$\begin{array}{l}\text { REG NA FOLHA DE } \\
\text { RESPOSTAS }\end{array}$} & \multicolumn{2}{|c|}{ TOTAL } \\
\hline & $\mathrm{N}$ & $\%$ & $\mathrm{~N}$ & $\%$ & $\mathrm{~N}$ & $\%$ & $\mathrm{~N}$ & $\%$ & $\mathrm{n}$ & $\%$ \\
\hline Sim & 57 & 5,6 & 467 & 46 & 24 & 2,4 & 1 & 0,1 & 594 & 54 \\
\hline Não & 18 & 1,8 & 393 & 39 & 51 & 5 & 0 & 0 & 462 & 46 \\
\hline Nulo ou em branco & 0 & 0 & 2 & 0,2 & 2 & 0,2 & 0 & 0 & 4 & 0,4 \\
\hline Registro na folha de respostas & 0 & 0 & 1 & 0,1 & 0 & 0 & 0 & 0 & 1 & 0,1 \\
\hline Total & 75 & 7,4 & 863 & 85 & 77 & 7,6 & 1 & 0,1 & 1016 & 100 \\
\hline
\end{tabular}

É ilustrado, na Tabela 3, o cruzamento entre as variáveis, correspondentes aos participantes terem realizado o teste do HIV e a necessidade do mesmo. Observa-se que, daqueles que responderam sim para o teste, 5,6\% dos participantes, também, responderam sim para necessário e apenas $1,8 \%$ responderam não. É relevante ressaltar que, do total de participantes, $54 \%$ responderam que o teste era necessário e 45,5\% responderam que não era. Esse resultado demonstra que os participantes não compreenderam a real necessidade da testagem, sendo que seria esperado que essa frequência estivesse próxima a $100 \%$. Ou ainda pode sugerir que os participantes não têm informações suficientes de onde, como e porque fazer. Não se deve descartar, ainda, o preconceito em relação a fazer a testagem, mesmo sabendo da sua importância.

Tabela 4

Teste HIV e Conhecimento Sobre HIV/aids ( $n=1016)$

\begin{tabular}{|c|c|c|c|c|c|c|c|c|c|c|}
\hline \multirow{3}{*}{$\begin{array}{l}\text { CONHECIMENTO SOBRE } \\
\text { HIVIAids }\end{array}$} & \multicolumn{10}{|c|}{ TESTE DO HIV } \\
\hline & \multicolumn{2}{|c|}{ SIM } & \multicolumn{2}{|c|}{ NÃO } & \multicolumn{2}{|c|}{$\begin{array}{l}\text { NULO OU } \\
\text { BRANCO }\end{array}$} & \multicolumn{2}{|c|}{$\begin{array}{l}\text { REG NA FOLHA } \\
\text { DE RESPOSTAS }\end{array}$} & \multicolumn{2}{|c|}{ TOTAL } \\
\hline & $\mathrm{n}$ & $\%$ & $\mathrm{~N}$ & $\%$ & $\mathrm{n}$ & $\%$ & $\mathrm{~N}$ & $\%$ & $\mathrm{~N}$ & $\%$ \\
\hline Conheço muito bem & 9 & 0,9 & 77 & 7,6 & 10 & 1 & 0 & 0 & 96 & 9,4 \\
\hline Conheço bem & 46 & 4,5 & 515 & 50,7 & 39 & 3,8 & 0 & 0 & 600 & 59,1 \\
\hline Conheço pouco & 17 & 1,7 & 243 & 23,9 & 24 & 2,4 & 1 & 0,1 & 285 & 28,1 \\
\hline Conheço muito pouco & 0 & 0 & 20 & 2 & 2 & 0,2 & 0 & 0 & 22 & 2,2 \\
\hline Não conheço nada & 2 & 0,2 & 2 & 0,2 & 2 & 0,2 & 0 & 0 & 6 & 0,6 \\
\hline Nula ou em branco & 1 & 0,1 & 6 & 0,6 & 0 & 0 & 0 & 0 & 4 & 0,7 \\
\hline Total & 75 & 7,4 & 863 & 84,9 & 77 & 7,6 & 1 & 0,1 & 1016 & 100 \\
\hline
\end{tabular}

A Tabela 4 apresenta a relação entre o teste do HIV e a autoavaliação do estudante, referente ao seu conhecimento sobre HIV/aids. Ressalta-se que, dos participantes que responderam sim para o teste, $5,4 \%$ consideraram que conhecem bem ou muito bem sobre o assunto e somente $1,7 \%$ responderam que conhecem pouco. 
Tabela 5

Teste HIV e Assistiu Algo Sobre HIV/aids ( $n=1016$ )

\begin{tabular}{|c|c|c|c|c|c|c|c|c|c|c|}
\hline \multirow{3}{*}{$\begin{array}{l}\text { ASSISTIU ALGO SOBRE } \\
\text { HIVIAIDS }\end{array}$} & \multicolumn{10}{|c|}{ TESTE DO HIV } \\
\hline & \multicolumn{2}{|c|}{ SIM } & \multicolumn{2}{|c|}{ NÃO } & \multicolumn{2}{|c|}{$\begin{array}{l}\text { NULO OU } \\
\text { BRANCO }\end{array}$} & \multicolumn{2}{|c|}{$\begin{array}{l}\text { REG NA FOLHA } \\
\text { DE RESPOSTAS }\end{array}$} & \multicolumn{2}{|c|}{ TOTAL } \\
\hline & $n$ & $\%$ & $\mathrm{~N}$ & $\%$ & $n$ & $\%$ & $\mathrm{~N}$ & $\%$ & $n$ & $\%$ \\
\hline Sim & 68 & 6,7 & 797 & 78 & 70 & 6,9 & 1 & 0,1 & 936 & 92 \\
\hline Não & 7 & 0,7 & 66 & 6,5 & 7 & 0,7 & 0 & 0 & 80 & 7,9 \\
\hline Total & 75 & 7,4 & 863 & 85 & 77 & 7,6 & 1 & 0,1 & 1016 & 100 \\
\hline
\end{tabular}

Por fim, a Tabela 5 demonstra a relação entre os participantes terem feito o teste do HIV e terem assistido algo sobre o assunto HIV/aids. Do total de participantes, 92,1\% responderam sim para assistiu algo sobre e, mesmo com esse grande percentual de acesso à informação, $84,9 \%$ dos participantes não fizeram o teste do HIV.

Os resultados mostraram, portanto, que houve associação significativa, entre os participantes terem buscado a testagem e considerá-la necessária $(\mathrm{p}=0,0)$ e entre buscar a testagem e conhecer algo sobre o assunto $(p=0,0)$. Porém, não houve associação significativa entre terem buscado a testagem e terem assistido algo sobre o assunto $(\mathrm{p}=0,7)$.

\section{DISCUSSÃO}

A partir dos resultados sobre a autoavaliação dos participantes, quanto ao conhecimento sobre HIV, pode-se depreender que é expressiva a frequência de respostas indicando contradições, no momento da identificação de situações de risco, para a contaminação pelo vírus.

$\mathrm{O}$ aumento de respostas afirmativas, dos participantes deste estudo, diante das possibilidades de transmissão do vírus HIV, quando aumentam os parceiros, pode estar relacionado a concepções equivocadas sobre o autocuidado e assim por diante. Os adolescentes, muitas vezes, acreditam que eles, especificamente, não estão em risco, pois sabem escolher bem o (a) parceiro (a), confiam nele (a), não têm múltiplos parceiros e, por isso mesmo, dispensam a proteção do preservativo. Tal circunstância pode ser apoiada nas posições de Jeolás (2003) e de Whaley (2000), quando afirmam, respectivamente, que há uma tendência otimista do jovem se avaliar e, também, que o conhecido representa, para a maioria, um sinônimo de familiar, de segurança e de proteção. $\mathrm{O}$ desconhecido, ao contrário, costuma significar insegurança, fonte de perigo.

A verificação de que $4,5 \%$ dos jovens participantes citaram, como exposição ao risco, outras formas de contato não sexuais, apesar de todas as campanhas informativas, pode ser compreendido, tendo como base a posição de Jeolás (2003), quando afirma que as representações da aids como doença do outro ainda estão presentes, nas explicações morais ou religiosas, e implicam em mecanismos de negação e de projeção do risco, para os homossexuais, prostitutas e travestis, ou para os pecadores, promíscuos e imorais. Na maior parte das vezes, estas representações reforçam a ideia de grupos de risco, tão presente no imaginário social, no início da epidemia da aids, ou a ideia de grupos e pessoas mais vulneráveis ao vírus, moralizando seus comportamentos, em lugar do conceito mais atual de comportamento de risco, inerente a própria condição humana e não a outras especificidades. A percepção do risco do HIV/aids é, ainda, em alguma medida, ancorada no modelo contagionista de doença, presente no coração da cultura ocidental, e, ainda, com grande força metafórica. A ideia de que todo contato constitui risco, o medo do contato físico, permanece e mesclase às diferentes maneiras de se compreender a infecção pelo HIV. Foi, aliás, a força da ideia de contágio que levou a atitudes de discriminação e até de exclusão, mais numerosas no início da epidemia, mas ainda existentes (Jeólas, 2003).

$\mathrm{O}$ estudo pode ser articulado a outros similares que também abordam o comportamento sexual e o risco, diante da concepção. Câmara (2005), por exemplo, detectou que os jovens estão bastante informados, acerca dos métodos anticoncepcionais disponíveis e que, mesmo assim, em alguns casos, esta informação, por si só, não é o suficiente e eles incidem em condutas de risco. De 230 que participaram de tal pesquisa, 
apenas 140 correspondem aos indivíduos que não apresentam comportamentos de risco sexual.

Com respeito à transmissão vertical, os resultados mostram que alguns jovens, ainda, desconhecem a transmissão da mãe para o bebê, o que pode resultar em uma não prevenção desta forma de contágio. $\mathrm{O}$ Brasil, ainda, conta com um contingente expressivo de crianças vivendo com HIV/Aids, mesmo sendo reduzidos, a praticamente zero, o risco de transmissão, se usadas as medidas eficazes. O problema é a disponibilidade de recursos financeiros, infraestrutura, pronta oferta de medicamentos antirretrovirais e capacitação de profissionais da saúde (Bastos \& Hacker, 2006), que dificulta as ações de prevenção.

Além disso, as respostas de alguns participantes, em não considerar necessária a realização do teste, demonstraram que eles não compreendem que esse reconhecimento pode ser, também, um meio de prevenção. Isso porque conhecer o status sorológico revela algum reconhecimento pela possibilidade de ter contraído o vírus e, mesmo em caso positivo, buscar, o mais breve possível, os recursos de saúde e, quem sabe, interromper a cadeia de transmissão. Dessa forma, os jovens podem se expor, em situações cotidianas, colocando-se em risco, visto a sua vulnerabilidade inerente. Informar os jovens não é o bastante; por exemplo, a distribuição de camisinhas e a demonstração de como usá-la não é uma informação estática e é isso que se necessita para a prevenção (Cassese, 2000). A análise de Jeolás (2005), referente às representações sociais sobre o risco da aids, entre jovens, afirma que o discurso da prevenção não consegue atingi-los, em suas ambivalências e tensões, e, por isso mesmo, exige avaliações e reformulações constantes.

$\mathrm{O}$ instrumento demonstrou ser adequado, apesar de eventuais limitações, quanto à interpretação das questões, pelos participantes, esperadas em alguma medida, considerando o fato da aplicação ser coletiva, no ambiente escolar. A composição da amostra, além de atender aos critérios que permitiram análises estatísticas robustas, coincide com o delineamento do estudo de Trajman e cols. (2003), que também optou pelo questionário autoaplicável, com jovens de dez escolas, só que ampliou para doenças sexualmente transmissíveis e comportamento sexual. Ainda quanto ao conteúdo das questões, ressalta-se que este estudo seguiu a orientação dos de Kornblit, Goménez, Diz, Petracci e Vujosevich (1997) e Monteiro e Vasconcelos-Raposo
(2006), ao contextualizar os conhecimentos, atitudes e crenças, face ao HIV/aids. Os estudos do tipo descritivo, que se conhecem como estudos KABP (estudos CAP-Conhecimentos, Atitudes e Práticas), apesar de algumas limitações, constituem um primeiro e necessário passo para a investigação, que tende a prosseguir com outras técnicas qualitativas de investigação (Kornblit e cols., 1997).

Mesmo que o planejamento do estudo não tenha, inicialmente, projetado alguma forma de intervenção, a coleta das informações junto às escolas oportunizou que o projeto flexibilizasse algumas ações, quanto à disponibilização de informações sobre o HIV/aids, junto aos jovens. Conforme descrito nos procedimentos, foi possível manter a exigência da pesquisa e atender a uma demanda pontual e de curto prazo, revelando, uma vez mais, o cuidado ético, no delineamento de projetos de pesquisa. Entende-se a necessidade de, constantemente, aliar a investigação à assistência, mesmo que não seja uma única equipe responsável pela implantação de ambas, sinalizando, assim, a tão desejável abordagem interdisciplinar, em que saúde e educação interagem de maneira produtiva e com resolutividade, potencializando os espaços de promoção de saúde, na família, na escola e na comunidade.

Comprova-se, portanto, a importância da atuação da Psicologia, nesse processo de redirecionamento, com o intuito de trabalhar com programas de prevenção, visando não apenas o repasse de informações, mas a internalização das mesmas. Os resultados sugerem que as campanhas preventivas focalizem as especificidades dos grupos de adolescentes, orientando no que se refere aos recursos e espaços de promoção de saúde a serem acessados, em caso de dúvidas acerca de seus hábitos e práticas, vinculados à sua vida de relação.

Os programas de prevenção deveriam oferecer mais do que uma simples conscientização sobre a epidemia e informações sobre aspectos biológicos da transmissão do HIV e da evolução para a aids. Não adianta apenas alertar os jovens, sobre os perigos do uso inconstante do preservativo ou dos perigos de ter múltiplos parceiros ou de não tratar as doenças sexualmente transmissíveis, que os colocam em risco. É necessário que se discutam a dinâmica dos relacionamentos e o significado do sexo seguro, nos diversos contextos afetivos (Antunes, Peres, Paiva, Stall, \& Hearst, 2002). 
Além disso, no meio acadêmico e de aplicação mais imediata, os resultados permitem orientar práticas de acadêmicos e profissionais da saúde e da psicologia, em particular, no planejamento de ações que efetivamente acessem ao grupo dos jovens, tão vulneráveis a expor-se aos riscos de doenças como as sexualmente transmissíveis, nas quais o HIV/aids se inclui. Um exemplo seria o desenvolvimento de oficinas sobre a sexualidade humana, com objetivos de informar conceitos básicos, eliminando tabus e mitos sexuais e reforçando a normalidade da sexualidade e a diversidade de práticas sexuais (Pérez, Hernández, Cartagena, \& Serrano-Garcia, 1999). Outra sugestão, nessa direção, é a educação preventiva, entre pares (Ayres, Freitas, Santos, Saletti, \& França, 2003), articulando os serviços disponíveis (Ayres, 2007; Paiva, Peres, \& Blessa, 2002; Spink, 2007). O objetivo das intervenções pode e deve ultrapassar a dimensão informativa e tentar sensibilizar, capacitar e organizar as pessoas (Ayres, 2007), para lidarem com suas manifestações sexuais, comportamentais e, mais que tudo, com seus vínculos afetivos. Do ponto de vista metodológico, tais práticas de investigação e/ou intervenção poderiam adotar delineamentos qualitativos ou quantitativos, dependendo dos objetivos e contextos a serem propostos, conforme sugere Günther (2006), quando detalha tais modalidades de sistematização do conhecimento.

Sugere-se que futuros estudos contemplem dimensões qualitativas, como aquelas propostas por Antunes e cols. (2002), quando realizaram oficinas de sexo mais seguro, para discutir as informações e o simbolismo da aids, a percepção de risco, as influências das normas de gênero, nas atitudes, o corpo erótico e o reprodutivo, o prazer sexual e a negociação do uso do preservativo. Tal experiência constatou que a percepção da capacidade de negociação do sexo seguro e das práticas sexuais, entre as mulheres, aumentou, depois das oficinas. Paiva (2006), em abordagem similar, propõe o encontro psicoeducativo como alternativa, em lugar do jovem receber, unicamente, informações e orientações, para que desenvolva autonomia e responsabilidade, para lidar com a sua própria sexualidade.

Ou, ainda, como propõem Trajman e cols. (2003), que os programas preventivos devem focalizar o comportamento, mais do que a transmissão da informação, e priorizar jovens de baixa renda familiar. A vulnerabilidade para o HIV/aids não é responsabilidade exclusiva do indivíduo, em particular, mas de um conjunto de fatores (Ayres, 2007), entre os quais devem ser elencados todos aqueles envolvidos com a saúde, a educação e o ambiente social, como um todo. Quanto às equipes de saúde, Silva e Cardoso (2008) recomendam atividades focais e trocas dialógicas, entre os agentes comunitários envolvidos nos programas de saúde da família, principalmente, quando se trata dos programas de atendimento aos portadores de HIV/ aids.

\section{CONSIDERAÇÕES FINAIS}

Os resultados desse estudo não devem ser examinados isoladamente, mas no contexto social em que está inserido. Ou seja, por um ou vários motivos, os jovens reproduzem e reconstroem sua posição, a partir de interferências da família, da escola e da comunidade em que interagem. Num estudo semelhante, Jeolás (2003) afirma que os jovens trazem respostas, sobre o que representa o risco da aids, em suas vidas, em forma de frases, parágrafos, pequenos relatos, depoimentos e desabafos, sendo possível constatar que eles se distanciam da linguagem racional do risco da aids, atuante, principalmente, na área da saúde. Ou seja, o risco, para eles, não se reduz à probabilidade de um evento negativo, mas diz respeito, muito mais, a valores e significados, atribuídos aos resultados deste evento, no contexto de suas vidas.

Sendo assim, as campanhas preventivas e outras ações referentes ao HIV/aids deveriam focalizar as especificidades dos jovens, orientando e potencializando os espaços de promoção de saúde, na família, na escola e na comunidade.

\section{REFERÊNCIAS}

Antunes, M. C., Peres, C. A., Paiva V., Stall, R., \& Hearst, N. (2002). Diferenças na prevenção da AIDS entre homens e mulheres jovens de escolas públicas em São Paulo, SP. Revista de Saúde Pública, 4, 88-95.

Ayres, J. R. (2007). AIDS: O que nos torna vulneráveis. Ciência e Profissão - Diálogos, 4, 34-35.

Ayres, J. R. C. M., Freitas, A. C., Santos, M. A. S., Saletti Filho, H. C., \& França Jr., I., (2003). Adolescência e aids: Avaliação de uma experiência de educação preventiva entre pares. Interface-Comunicação, Saúde, Educação, 7, 123-138.

Bastos, F. I., \& Hacker, M. A. (2006). Pesquisas brasileiras psicossociais e operacionais face às metas do UNGASS. Revista de Saúde Pública, 40, 42-51.

Câmara, S. G. (2005). Comportamento de risco entre jovens. Psico, 36, 89-97.

Camargo, B. V., \& Bárbara, A. (2004). Efeitos de panfletos informativos sobre a AIDS em adolescentes. Psicologia: Teoria e Pesquisa, 20, 279-287. 
Cassese, J. (2000). Trauma sexual e risco para o HIV. Em T. Pinto \& I. S. Telles (Orgs.), AIDS e escola: Reflexões e propostas do EDUCAIDS (2 ${ }^{\mathrm{a}}$ ed.) (pp. 43-50). São Paulo: Cortez.

Dall'Agnol, R. S. (1999). Prevenção da AIDS na adolescência: Um desafio a psicologia contemporânea. Tese de doutorado não-publicada, Pontifícia Universidade Católica do Rio Grande do Sul, Porto Alegre.

Duarte, V., Mezzomo, G., \& Bordin, M. (2007). Reações do sujeito frente ao diagnóstico de sorologia positiva para o vírus AIDS/HIV. Atlas Psico,1(2), 18-28. Retirado de http://www. atlaspsico.com.br/Revista_ATLASPSICO_02.pdf

Figueiró, M. N. D., \& Ribeiro, P. R. M. (Orgs.) (2006). Adolescência em questão: Estudos sobre sexualidade. São Paulo: Cultura Acadêmica.

Günther, H. (2006). Pesquisa qualitativa versus pesquisa quantitativa: Esta é a questão? Série: Textos de Psicologia Ambiental, n. 7. Laboratório de Psicologia Ambiental da Universidade de Brasília. Retirado de http://www.psi-ambiental.net/pdf/07Qual Quant.pdf

Jeolás, L. S. (2003). Os jovens e o imaginário da AIDS: Notas para uma construção social do risco. Campos: Revista de Antropologia Social, 4, 93-112.

Jeolás, L. S. (2005). Imaginário do risco da AIDS entre jovens: Vulnerabilidade e prevenção. Serviço Social em Revista, 2, 121-134. Retirado de http://www.uel.br/revistas/ssrevista/n1v2. pdf

Jerusalinsky, A. (2004). Adolescência e contemporaneidade. Em A. Mello, A. L. S. Castro \& M. Geiger (Orgs.), Conversando sobre adolescência e contemporaneidade (pp. 54-65). Porto Alegre: Libretos.

Kornblit, A. L., Goménez, L., Diz, A. M. M., Petracci, M., \& Vujosevich, J. (1997). Y el SIDA está entre nosotros. Buenos Aires: Corregidor.

López, L. (2004). ¿Se puede prevenir el sida? Madrid: Biblioteca Nueva.

Maticka-Tyndale, E., \& Brouillard-Coyle, C. (2006). The effectiveness of community interventions targeting HIV and AIDS prevention at young people in developing countries. Technical Report Series, 938. Retirado de http://www.accessmylibrary. com/article-1G1-151187467/8-effectiveness-communityinterventions.html

Monteiro, M. J., \& Vasconcelos-Raposo, J. (2006). Contextualizar os conhecimentos, atitudes e crenças face ao VIH/SIDA: Um contributo para aperfeiçoar o caminho a percorrer. Psicologia, Saúde \& Doenças, 7, 125-136. Retirado de http://www.scie lo.oces.mctes.pt/pdf/psd/v7n1/v7n1a11.pdf

Niimi, R. (2000). Apresentação. Em T. Pinto \& I. S. Telles (Orgs.), AIDS e escola: Reflexões e propostas do EDUCAIDS ( $2^{\mathrm{a}}$ ed.) (pp. 9-10). São Paulo: Cortez.
Paiva, V. (2006). Sexualidade na saúde pública. Ciência e Profissão - Diálogos, 3, 32-33.

Paiva, V., Peres, C., \& Blessa, C. (2002). Jovens e adolescentes em tempos de AIDS: Reflexões sobre uma década de trabalho de prevenção. Psicologia USP, 13, 55-78.

Pérez, E. A., Hernández, F., Cartagena, M. R. H., \& SerranoGarcia, I. (1999, julho).

¿Qué conoce un grupo de universitarias puertorriqueñas sobre su anatomía y fisiología sexual y su relación con la sexualidad? Trabalho apresentado no XXVII Congresso Interamericano de Psicologia, Caracas.

Programa Nacional DST e Aids (2007). Portal informativo sobre aids e outras doenças sexualmente transmissíveis. Retirado de www.aids.gov.br

Santos, V. L., \& Santos, C. E. (1999). Adolescência, jovens e AIDS no Brasil. Cadernos, Juventude, Saúde e Desenvolvimento, 1, 213-222. Retirado de http://www.adolec.br/bvs/adolec/ $\mathrm{P} /$ pdf/cadernos1.pdf

Silva, N. H. L. P., \& Cardoso, C. L. (2008). Agentes comunitários de saúde: Sentidos acerca do trabalho em HIV/AIDS. Psicologia \& Sociedade, 20, 257-266.

Spink, M. J. (2007). A atuação como profissional de saúde. Ciência e Profissão-Diálogos, 3, 46-48.

Taylor, M., Dlamini, S. B., Kagoro, H., Jinabhai, C. C., \& Vries, H. (2003). Understanding high school students risk behaviors to help reduce the HIV/AIDS epidemic in Kwazulu-Natal, South Africa. Journal of School Health, 73, 97-100.

Trajman, A., Belo, M. T., Teixeira E. G., Dantas V. C. S., Salomão, F. M., Cunha, A. J., \& Ledo, A. (2003). Conhecimento sobre DST/AIDS e comportamento sexual entre estudantes do ensino médio no Rio de Janeiro, Brasil. Cadernos de Saúde Pública, 19, 127-133.

Wagner, T., Maggi, A., Souza, C., \& Souza, R. (2010). Estudantes universitários em tempos de HIV: O contexto da testagem. Interação em Psicologia, 14, 61-71

Whaley, A. L. (2000). Differential risk perceptions for unintended pregnancy, STDs, and HIV/AIDS among urban adolescents: Some preliminary findings. Journal of Genetic Psychology, 161, 435-452. Retirado de http://heldref-publications.meta press.com/app/home/contribution.asp?referrer=parent\&backto $=$ issue,4,9;journal,41,56;linkingpublicationresults, 1:119924,1

Recebido: $25 / 06 / 2008$

Última revisão: $15 / 09 / 2010$

Aceite final: 23/09/2010 